\title{
Effect of the Direct Renin Inhibitor Aliskiren in the Prevention of Experimental Contrast-Induced Nephropathy in the Rat
}

\author{
Alla Eldeen Kedrah ${ }^{\mathrm{a}}$ Elif Ari $^{\mathrm{b}}$ Yesim Alahdab $^{\mathrm{a}} \quad$ Cuma Bulent Gul $^{\mathrm{d}}$ \\ Beyza Macunluoglu $^{\mathrm{b}}$ Aydin Atakan $^{\mathrm{b}}$ Ebru Asicioglu ${ }^{\mathrm{b}}$ Fulya Cakalagaoglu $^{\mathrm{c}}$ \\ Mehmet Koc ${ }^{\text {b }}$ \\ Departments of a Gastroenterology, ${ }^{b}$ Nephrology and ${ }^{c}$ Pathology, Marmara University, School of Medicine, \\ Istanbul, and d Department of Nephrology, Uludag University Medical School, Bursa, Turkey
}

\section{Key Words}

Aliskiren · Contrast-induced nephropathy · Acute renal

failure $\cdot$ Experimental study

\begin{abstract}
Background: Renal vasoconstriction, activated by the reninangiotensin system, plays a pivotal role in the pathogenesis of contrast-induced nephropathy (CIN). The purpose of this study was to evaluate the effect of aliskiren, a direct renin inhibitor, for the prophylaxis of experimental CIN in the rat. Methods: Thirty-two Wistar albino rats were divided into four groups of 8 rats each, namely the control (C), aliskiren $(\mathrm{A})$, contrast media (CM) and aliskiren plus contrast media (ACM) groups. Aliskiren was given orally at a dose of $50 \mathrm{mg} /$ $\mathrm{kg} /$ day once daily for 5 consecutive days. CIN was induced by intravenous administration of indomethacin, N-nitro-L-arginine methyl ester and high-osmolar contrast medium meglumine amidotrizoate. Renal function parameters, kidney histology and tubular expression of vascular endothelial growth factor were determined. Results: Mean serum creatinine was significantly lower $(p<0.001)$ and mean creatinine clearance was higher $(p<0.001)$ in the ACM group compared with the CM group. However, there were no differences between the ACM and CM groups in terms of tubular
\end{abstract}

\section{KARGER}

Fax +4161306 1234

E-Mail karger@karger.ch

www.karger.com
(C) 2012 S. Karger AG, Basel

$1420-4096 / 12 / 0356-0425 \$ 38.00 / 0$

Accessible online at: www.karger.com/kbr necrosis, proteinaceous casts, medullary congestion and vascular endothelial growth factor expression. Conclusion: Our preliminary data seem to suggest a potential role of aliskiren for the prophylaxis of CIN in an experimental rat model.

Copyright $\odot 2012$ S. Karger AG, Basel

\section{Introduction}

Contrast-induced nephropathy (CIN), defined as the rapid deterioration in renal function after administration of contrast medium (CM) without other specific causes, is a common cause of acute kidney injury [1-3]. Patients who develop CIN are at a higher risk of morbidity and mortality compared with controls $[4,5]$. For these reasons, precautionary maneuvers are warranted to reduce the incidence of this complication, especially in subjects with an underlying renal insufficiency [6-8]. Unfortunately, CIN remains poorly understood despite decades of investigation, and effective means of reducing its incidence are still lacking [9].

\section{A.E. Kedrah and E. Ari contributed equally to this work.}


Previous data have shown that the renin-angiotensinaldosterone system (RAAS) may play a role in the pathophysiology of CIN [10]. However, there is still controversy concerning the clinical usefulness of RAAS blockade in the prevention of this condition [11]. Some studies have demonstrated that chronic medication with angiotensinconverting enzyme inhibitors (ACE-I) or angiotensin II receptor antagonists may represent a risk factor for CIN [12-14]. In contrast, other authors have reported a protective effect of ACE-I in patients with chronic kidney disease exposed to CM [10].

Aliskiren - 2(S),4(S),5(S),7(S)-N-(2-carbamoyl-2-methylpropyl)-5-amino-4-hydroxy-2,7-diisopropyl-8-[4-methoxy-3-(3-methoxypropoxy)phenyl]-octanamide hemifumarate - is a direct renin inhibitor that has been approved for lowering arterial blood pressure $[15,16]$. The drug occupies a specific site within the enzymatic pocket of the renin/prorenin receptor, thereby blocking the function of this enzyme [17]. Because the RAAS cascade begins with renin and because aliskiren may exert renoprotective effects [18-20], we aimed to examine the effects of aliskiren for prevention of CIN using a rat model. In addition - as aliskiren may reduce vascular endothelial growth factor (VEGF) expression [21], which is increased in acute kidney injury [22] - we assessed whether tubular VEGF expression can be diminished by the administration of aliskiren immediately before the experimental induction of CIN. The potential usefulness of direct renin inhibition for preventing CIN has not been previously examined neither in animal models nor in humans. This strategy is particularly interesting as a complete blockade with the use of ACE-I and angiotensin receptor blockers with or without aldosterone receptor blockers is not easy to achieve, and side effects are not uncommon [18].

\section{Methods}

\section{Ethics}

All in vivo experiments were reviewed and approved by the Committee of Ethics on Animal Experiments, Marmara University School of Medicine, Istanbul, Turkey, according to the Guidelines of the American Physiological Society. This study also conforms with the Guide for the Care and Use of Laboratory Animals published by the US National Institutes of Health (NIH Publication No. 85-23, revised 1996).

\section{Animals}

Healthy male albino rats of Wistar strain weighing 240-270 g (7 weeks old) bred locally in the central animal house were selected for the study and randomly assigned to four groups of 8 animals each. They were housed in standard stainless steel hanging cages in a vivarium with controlled temperature $\left(22-25^{\circ} \mathrm{C}\right)$, humidity (35-50\%), and photocycle (12 h light/12 h dark). The animals were placed in metabolic cages to record water intake and 24-hour urine collection.

\section{Experimental Design}

The animals $(\mathrm{n}=32)$ were allocated randomly into four equal groups of 8 rats each. Animals in the control group $(C)$ received saline injections into the tail vein 3 times at 15 -min intervals. Rats in the aliskiren (A) group received aliskiren (Novartis Pharmaceutical, New York, N.Y., USA) $50 \mathrm{mg} / \mathrm{kg} /$ day by oral gavage once daily for 5 consecutive days before the experimental induction of CIN. Rats in the CM group underwent experimental induction of CIN by intravenous administration of indomethacin $(10 \mathrm{mg} / \mathrm{kg})$, $\mathrm{N}$-nitro-L-arginine methyl ester $(10 \mathrm{mg} / \mathrm{kg}$, twice at 15 and 30 min) and high-osmolar contrast medium meglumine amidotrizoate $60 \%$ (6 ml/kg; Urovist-Angiographin, Schering AG, Germany), as previously described $[23,24]$. Rats in the aliskiren plus $\mathrm{CM}$ (ACM) group received aliskiren $50 \mathrm{mg} / \mathrm{kg} /$ day by oral gavage once daily for 5 consecutive days before the experimental induction of CIN. All rats were then allowed to recover for $24 \mathrm{~h}$ in metabolic cages. Twenty-four-hour urine samples were collected for the assessment of creatinine clearance $(\mathrm{CrCl})$ and fractional excretion of sodium. Blood samples were obtained from the abdominal aorta under general anesthesia after intraperitoneal injection of ketamine (50 mg/kg Ketalar, Pfizer, Istanbul, Turkey). Serum was separated and aliquots were stored at $-80^{\circ} \mathrm{C}$ until analysis.

\section{Renal Function Parameters}

Creatinine measurements in serum and urine were performed using a standard spectrophotometric assay (Modular P, Roche Diagnostics GmbH, Penzberg, Germany). Sodium concentrations in serum and urine were measured by ion-selective electrodes (Modular ISE, Roche Diagnostics). $\mathrm{CrCl}$ was calculated according to the formula: UV/P, where $U$ represents the urinary creatinine concentration $(\mathrm{mg} / \mathrm{dl}), \mathrm{V}$ is the urinary collection volume $(\mathrm{ml} /$ $\mathrm{min} / 100)$, and $\mathrm{P}$ is the serum creatinine concentration $(\mathrm{mg} / \mathrm{dl}$ ). $\mathrm{CrCl}$ values were expressed as $\mathrm{ml} / \mathrm{min} / 100 \mathrm{~g}$ body weight. Fractional excretion of sodium was calculated as follows: (urine sodium/serum sodium $) \times($ serum creatinine/urine creatinine $) \times$ 100 .

\section{Histology}

Kidneys were removed from mice killed by sodium pentobarbital injection ( $100 \mathrm{mg} / \mathrm{kg}$ intraperitoneally), placed in fixative for $4 \mathrm{~h}$ at $4^{\circ} \mathrm{C}$ and then transferred to $2 \%$ paraformaldehyde at $4{ }^{\circ} \mathrm{C}$ until paraffin embedding, sectioning and hematoxylin and eosin staining. Tubular necrosis, proteinaceous casts and medullary congestion were analyzed semiquantitatively according to previous methodology [23]. Tubular necrosis and proteinaceous casts were graded as follows: $0=$ no damage; $1=$ mild (unicellular, patchy isolated damage); $2=$ moderate (damage $<25 \%$ ); $3=$ severe (damage between 25 and 50\%), and $4=$ very severe ( $>50 \%$ damage). The degree of medullary congestion was defined as: $0=$ no congestion; 1 = mild (vascular congestion with identification of erythrocytes by $\times 400$ magnification); $2=$ moderate (vascular congestion with identification of erythrocytes by $\times 200$ magnification); 3 = severe (vascular congestion with identification of erythrocytes by $\times 100$ magnification), and $4=$ very severe (vascular congestion with identification of erythrocytes by $\times 40$ magnification) [23]. Evaluations were made in a blinded manner. 
Table 1. Renal function parameters in the four treatment groups ( $\mathrm{n}=8$ rats each)

\begin{tabular}{lllll}
\hline & C & A & CM & ACM \\
\hline Serum creatinine, $\mathrm{mg} / \mathrm{dl}$ & $0.37 \pm 0.54$ & $0.45 \pm 0.08$ & $1.01 \pm 0.43$ & $0.52 \pm 0.12^{*}$ \\
Creatinine clearance, $\mathrm{ml} / \mathrm{min}$ & $1.92 \pm 0.67$ & $1.42 \pm 0.50$ & $\begin{array}{r}0.57 \pm 0.37 \\
1.8 \pm 2.19\end{array}$ & $\begin{array}{l}0.90 \pm 0.23 \pm 0.07^{*} \\
\text { Fractional excretion of sodium, \% }\end{array}$ \\
\hline
\end{tabular}

Values are expressed as means \pm standard deviations. ${ }^{*} \mathrm{p}<0.001$ versus the CM group.

Table 2. Histology findings in the four treatment groups $(\mathrm{n}=8$ rats each)

\begin{tabular}{lllll}
\hline & C & A & CM & ACM \\
\hline Tubular necrosis & $0.25 \pm 0.46$ & $0.28 \pm 0.48$ & $2.50 \pm 0.53$ & $2.75 \pm 0.46$ \\
Proteinaceous casts & $0.37 \pm 0.51$ & $0.14 \pm 0.37$ & $2.87 \pm 0.64$ & $3.00 \pm 0.53$ \\
Medullary congestion & $0.75 \pm 0.88$ & $0.85 \pm 0.37$ & $3.50 \pm 0.53$ & $3.00 \pm 0.53$ \\
VEGF expression & $0.50 \pm 0.53$ & $0.42 \pm 0.53$ & $2.62 \pm 0.51$ & $2.37 \pm 0.51$ \\
\hline
\end{tabular}

Values are expressed as means \pm standard deviations. No significant differences were found in the CM and ACM groups.

\section{Immunohistochemistry for VEGF}

Immunohistochemistry for VEGF in the tubular cells of the kidney outer medulla was performed on 3 - $\mu$ m-thick renal sections using an avidin-biotin-peroxidase technique. Briefly, paraffin-embedded tissue sections were cleared in xylene and rehydrated in a series of ethanol washes. Endogenous peroxidase activity was inhibited by using 3\% hydrogen peroxide. Antigen retrieval was performed by microwaving sections in citrate buffer (pH 6). Sections were blocked in phosphate-buffered saline $(\mathrm{pH}$ 7.4) for $20 \mathrm{~min}$ at room temperature. Protein blockage was performed to reduce nonspecific background staining. The sections were incubated for 30 min with a primary anti-VEGF antibody (Ab-1, RB-222-R7; Thermo Fisher Scientific, Fremont, Calif., USA) and subsequently exposed for $10 \mathrm{~min}$ to a biotin-conjugated secondary antibody (UltraVision Detection System; TP-015-HD; Thermo Fisher Scientific). This biotinylated secondary antibody was visualized after reaction with streptavidin-peroxidase conjugate and subsequent addition of diaminobenzidine. Negative controls were performed by omitting the primary antibody. According to previous methodology [23], the percentage of VEGFpositive tubular cells was semiquantitatively assessed by two independent observers and scored as: $0=$ negative, no expression of VEGF; 1 = weak staining, $0-25 \%$ of tubular cells show positive staining; $2=$ moderate staining, $>25-75 \%$ of tubular cells with positive staining, and $3=$ strong staining, $>75-100 \%$ of tubular cells [23].

\section{Data Analysis}

The statistical package SPSS 14.0 (SPSS Inc., Chicago, Ill., USA) was used for data analysis. Shapiro-Wilk tests were performed to check for normal distribution. According to these tests, continuous data were normally distributed and only parametric analyses were exploited. Group comparisons were performed using one-way ANOVA followed by Tukey's pairwise multiple comparison test. Data are presented as means \pm standard deviations, and values of $\mathrm{p}<0.05$ (two-tailed) were considered statistically significant. As this study was essentially exploratory in nature, a Bonferroni adjustment was not performed.

\section{Results}

The baseline characteristics were well balanced among the four treatment groups. All animals survived to study completion.

\section{Renal Function Parameters}

Table 1 shows the renal function parameters in the four treatment groups. Serum creatinine did not differ in the $\mathrm{C}$ and $\mathrm{A}$ groups. As expected, creatinine levels increased significantly in the CM group compared with control animals $(\mathrm{p}<0.001)$. However, there were no significant differences in creatinine values in the ACM group compared with controls. The mean $\mathrm{CrCl}$ did not differ in the $\mathrm{C}$ and A groups. $\mathrm{CrCl}$ was significantly lower in the CM than in the $\mathrm{C}$ group $(\mathrm{p}<0.001)$, but no differences were seen in the ACM group compared with control rats. The fractional excretion of sodium was sim- 
Fig. 1. Presence of areas of tubular necrosis in the outer medulla of CM rats (hematoxylin and eosin; a) and ACM rats (b). $\times 200$.

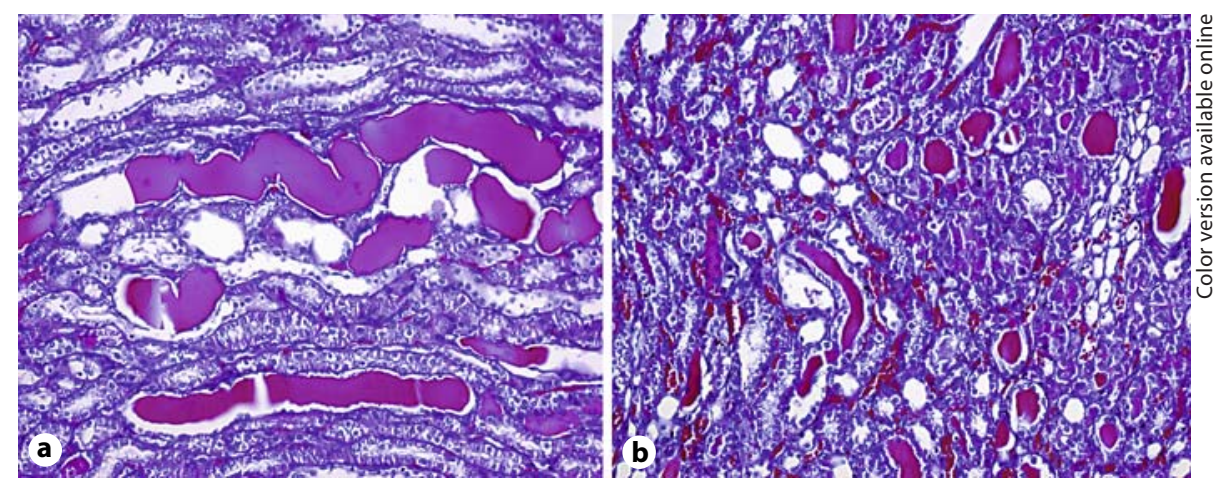

Fig. 2. Intense expression of VEGF in the outer medulla of CM rats (a) and ACM rats (b). $\times 200$.

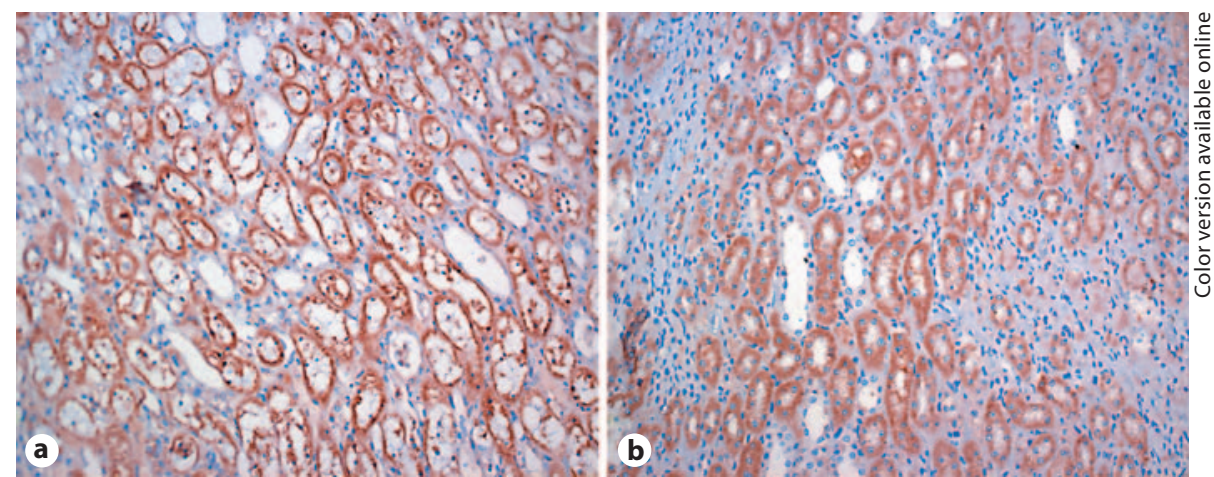

ilar in the $\mathrm{C}$ and $\mathrm{A}$ groups. The mean fractional excretion of sodium increased significantly in the CM group compared with the $\mathrm{C}$ group $(\mathrm{p}<0.001)$. On the other hand, this parameter was significantly lower in the ACM than in the CM group $(\mathrm{p}<0.001)$.

\section{Histology}

The histological findings in the four treatment groups are reported in table 2 . There were no significant differences in the mean score for the degree of tubular necrosis in the four study groups. Similarly, we found no differences in the mean scores of proteinaceous casts and medullary congestion (fig. 1).

\section{Immunohistochemistry for VEGF}

As expected, the mean immunohistochemical score for VEGF was significantly higher in the CM group than in the control group ( $<<0.001$; table 2). However, the VEGF expression was similar in the ACM and CM groups (fig. 2).

\section{Discussion}

In the present experimental study, we have shown for the first time that CIN prophylaxis using the direct angiotensin inhibitor aliskiren is effective in attenuating the acute deterioration in renal function in the rat. However, aliskiren did not reduce tubular necrosis, proteinaceous casts and medullary congestion, as well as VEGF immunoexpression associated with the development of CIN.

CIN ranks third in leading causes of hospital-acquired renal failure, and this condition has been associated with increased costs of medical care during hospitalization and prolongation of hospital stay [25]. Although multiple pharmacological prevention strategies - including the use of dopamine, fenoldopam, atrial natriuretic peptide, mannitol, postprocedural diuretics, endothelin receptor antagonists, calcium channel blockers, prostaglandin $\mathrm{E}_{1}$, aminophylline or theophylline, statins, and ascorbic acid - have been proposed, results have been mixed [26].

The two major theories of the pathogenesis of CIN are renal vasoconstriction and direct cytotoxic effects of contrast agents $[3,25]$. In human subjects, renal blood flow 
has been reported to decrease by $30-45 \%$ within $2-4 \mathrm{~h}$ after the injection of $\mathrm{CM}$, which may lead to deterioration in renal functions because of medullary hypoxia $[27,28]$. Another possible cause is the direct cytotoxic effect of the radiocontrast agent, which can cause renal tubular injury [29]. The results of the present study seem to suggest that pretreatment with aliskirin before the injection of a $\mathrm{CM}$ may have benefits in terms of serum creatinine, $\mathrm{CrCl}$ and fractional excretion of sodium. However, histological parameters did not improve significantly. Based on these findings, we speculate that aliskiren could have exerted its beneficial effects in the prevention of CIN mainly through prerenal mechanisms. Accordingly, direct renin inhibition has been shown to increase renal blood flow to a significantly greater degree than angiotensin-converting enzyme inhibition [30]. The increase in renal blood flow induced by aliskiren may be a response to angiotensin AT1 receptor-dependent reduction in vascular tone in the efferent arteriole. Reduced vascular tone in the efferent glomerular arteriole could be responsible for the decrease in intraglomerular pressure [30]. Gross et al. [19] have recently suggested that aliskiren may be renoprotective regardless of its effect on the vascular tone. Indeed, aliskiren has been shown to have antifibrotic and antiproteinuric effects in a nonhypertensive mouse model for progressive renal fibrosis [19]. Another important feature of aliskiren is its partitioning in the renal tissue, where it localizes in the glomeruli and in the renal cortical arteries at concentrations several fold higher than in plasma [31]. While this compound seems to be useful to prevent the histological effects of chronic renal injury, our report seems to suggest that aliskiren pretreatment does not improve kidney histology after administration of CM. Taken together, our findings suggest that the observed improvements in renal function parameters after the induc- tion of CIN are not mirrored by significant histological changes. Therefore, it is likely that the observed effects of direct angiotensin inhibition in the prophylaxis of CIN could mainly be exerted through prerenal mechanisms.

Several caveats of this report merit comment. The small sample size is an obvious limitation. Although this is an experimental study of CIN prevention in the rat, our report provides a proof of concept and could have implications for further clinical research in humans. Dosage regimens for human use should be further evaluated as the protective effect in clinical practice should be dose dependent [30]. Another important limitation is that we did not attempt to measure proteinuria in the rats.

These limitations notwithstanding, we demonstrate for the first time that administration of aliskiren improves renal function parameters in a rat model of CIN but did not ameliorate tubular necrosis, proteinaceous casts and medullary congestion in the kidney after the administration of contrast. While aliskiren may have a role in the prophylaxis of CIN, further animal and clinical studies are needed before any definite conclusion can be drawn. The observed benefits of aliskiren administration can be associated with an improvement in renal blood flow.

\section{Acknowledgements}

The authors are thankful to Prof. Cetin Ozener for his excellent technical support. This work was supported by a grant from the Department of Nephrology, Marmara University School of Medicine, Istanbul, Turkey.

\section{Disclosure Statement}

No conflicts of interest declared.

\section{References}

$>1$ Mautone A, Brown JR: Contrast-induced nephropathy in patients undergoing elective and urgent procedures. J Interv Cardiol 2010;23:78-85.

-2 Sterling KA, Tehrani T, Rudnick MR: Clinical significance and preventive strategies for contrast-induced nephropathy. Curr Opin Nephrol Hypertens 2008;17:616-623.

$\checkmark 3$ Bartorelli AL, Marenzi G: Contrast-induced nephropathy. J Interv Cardiol 2008;21:7485.
4 Rudnick M, Feldman H: Contrast-induced nephropathy: what are the true clinical consequences? Clin J Am Soc Nephrol 2008;3: 263-272.

5 Mehran R: Contrast-induced nephropathy remains a serious complication of PCI. J Interv Cardiol 2007;20:236-240.

$\checkmark 6$ Al-Ghonaim M, Pannu N: Prevention and treatment of contrast-induced nephropathy. Tech Vasc Interv Radiol 2006;9:42-49.

7 Van Praet JT, De Vriese AS: Prevention of contrast-induced nephropathy: a critical review. Curr Opin Nephrol Hypertens 2007; $16: 336-347$.
8 Schweiger MJ, Chambers CE, Davidson CJ, Blankenship J, Bhalla NP, Block PC, Dervan JP, Gasperetti C, Gerber L, Kleiman NS, Krone RJ, Phillips WJ, Siegel RM, Uretsky BF, Laskey WK: Prevention of contrast induced nephropathy: recommendations for the high risk patient undergoing cardiovascular procedures. Catheter Cardiovasc Interv 2007; 69:135-140.

$>9$ Lameire NH: Contrast-induced nephropathy - prevention and risk reduction. Nephrol Dial Transplant 2006;21:11-23. 
10 Gupta RK, Kapoor A, Tewari S, Sinha N, Sharma RK: Captopril for prevention of contrast-induced nephropathy in diabetic patients: a randomised study. Indian Heart J 1999;51:521-526.

$11 \mathrm{Li} \mathrm{X,} \mathrm{Li} \mathrm{T,} \mathrm{Cong} \mathrm{H:} \mathrm{Is} \mathrm{angiotensin-converting}$ enzyme inhibitor a contraindication for contrast-induced nephropathy prophylaxis? A review about its paradox. Cardiovasc Ther DOI: 10.1111/j.1755-5922.2011.00299.x.

$\checkmark 12$ Patel K, King CA, Jovin IS: Angiotensin-converting enzyme inhibitors and their effects on contrast-induced nephropathy after cardiac catheterization or percutaneous coronary intervention. Cardiovasc Revasc Med 2011;12:90-93

$>13$ Onuigbo MA, Onuigbo NT: Does renin-angiotensin aldosterone system blockade exacerbate contrast-induced nephropathy in patients with chronic kidney disease? A prospective 50-month Mayo Clinic study. Ren Fail 2008;30:67-72.

14 Cirit M, Toprak O, Yesil M, Bayata S, Postaci N, Pupim L, Esi E: Angiotensin-converting enzyme inhibitors as a risk factor for contrast-induced nephropathy. Nephron Clin Pract 2006;104:c20-c27.

$\checkmark 15$ Barrios V, Escobar C: Aliskiren in the management of hypertension. Am J Cardiovasc Drugs 2010;10:349-358.

16 Riccioni G: Aliskiren in the treatment of hypertension and organ damage. Cardiovasc Ther 2011;29:77-87.

17 Ichihara A, Sakoda M, Kurauchi-Mito A, Narita T, Kinouchi K, Bokuda K, Itoh H: New approaches to blockade of the renin-angiotensin-aldosterone system: characteristics and usefulness of the direct renin inhibitor aliskiren. J Pharmacol Sci 2010;113:296300
8 Trimarchi H: Role of aliskiren in blood pressure control and renoprotection. Int J Nephrol Renovasc Dis 2011;4:41-48.

19 Gross O, Girgert R, Rubel D, Temme J, Theissen S, Müller GA: Renal protective effects of aliskiren beyond its antihypertensive property in a mouse model of progressive fibrosis. Am J Hypertens 2011;24:355-361.

20 Rakusan D, Kujal P, Kramer HJ, Husková Z, Vanourková Z, Vernerová Z, Mrázová I, Thumová M, Cervenka L, Vanecková I: Persistent antihypertensive effect of aliskiren is accompanied by reduced proteinuria and normalization of glomerular area in Ren-2 transgenic rats. Am J Physiol Renal Physiol 2010;299:F758-F766.

21 Wilkinson-Berka JL, Tan G, Binger KJ, Sutton L, McMaster K, Deliyanti D, Perera G, Campbell DJ, Miller AG: Aliskiren reduces vascular pathology in diabetic retinopathy and oxygen-induced retinopathy in the transgenic (mRen-2)27 rat. Diabetologia 2011;54:2724-2735.

22 Doi K, Noiri E, Fujita T: Role of vascular endothelial growth factor in kidney disease. Curr Vasc Pharmacol 2010;8:122-128.

23 Ari E, Yilmaz Y, Kedrah AE, Alahdab Y Cakalagaoglu F, Arikan H, Kocak H, Macunluoglu B, Atakan A, Kahveci A, Asicioglu E, Tuglular S, Ozener C: Protective effect of the vasopressin agonist terlipressin in a rat model of contrast-induced nephropathy. Am J Nephrol 2011;33:269-276.

24 Toprak O, Cirit M, Tanrisev M, Yazici C, Canoz O, Sipahioglu M, Uzum A, Ersoy R, Sozmen EY: Preventive effect of nebivolol on contrast-induced nephropathy in rats. Nephrol Dial Transplant 2008;23:853-859.
25 Persson PB, Hansell P, Liss P: Pathophysiology of contrast medium-induced nephropathy. Kidney Int 2005;68:14-22.

26 Kagan A, Sheikh-Hamad D: Contrast-induced kidney injury: focus on modifiable risk factors and prophylactic strategies. Clin Cardiol 2010;33:62-66.

27 Russo D, Minutolo R, Cianciaruso B, Memoli B, Conte G, De Nicola L: Early effects of contrast media on renal hemodynamics and tubular function in chronic renal failure. J Am Soc Nephrol 1995;6:1451-1458.

28 Tumlin JA, Wang A, Murray PT, Mathur VS: Fenoldopam mesylate blocks reductions in renal plasma flow after radiocontrast dye infusion: a pilot trial in the prevention of contrast nephropathy. Am Heart J 2002;143: 894-903.

29 Heinrich MC, Kuhlmann MK, Grgic A, Heckmann M, Kramann B, Uder M: Cytotoxic effects of ionic high-osmolar, nonionic monomeric, and nonionic iso-osmolar dimeric iodinated contrast media on renal tubular cells in vitro. Radiology 2005;235:843849.

30 Müller DN, Luft FC: Direct renin inhibition with aliskiren in hypertension and target organ damage. Clin J Am Soc Nephrol 2006; 1 : 221-228.

31 Feldman DL, Jin L, Xuan H, Contrepas A, Zhou Y, Webb RL, Mueller DN, Feldt S, Cumin F, Maniara W, Persohn E, Schuetz H, Jan Danser AH, Nguyen G: Effects of aliskiren on blood pressure, albuminuria, and (pro)renin receptor expression in diabetic TG(mRen-2)27 rats. Hypertension 2008;52: 130-136. 